Article

\title{
Membrane-Cryogenic Post-Combustion Carbon Capture of Flue Gases from NGCC
}

\author{
Colin A. Scholes ${ }^{1, *}$, Minh T. Ho ${ }^{2}$ and Dianne E. Wiley ${ }^{2}$ \\ 1 Department of Chemical and Biomolecular Engineering, The University of Melbourne, \\ Melbourne 3010, Australia \\ 2 School of Chemical Engineering, University of New South Wales, Kensington 2052, Australia; \\ minh.ho@unsw.edu.au (M.T.H.); d.wiley@unsw.edu.au (D.E.W.) \\ * Correspondence: cascho@unimelb.edu.au; Tel.: +61-3-9035-8289
}

Academic Editor: Gustavo A. Fimbres Weihs

Received: 26 February 2016; Accepted: 19 April 2016; Published: 22 April 2016

\begin{abstract}
Membrane gas separation for carbon capture has traditionally been focused on high pressure applications, such as pre-combustion capture and natural gas sweetening. Recently a membrane-cryogenic combined process has been shown to be cost competitive for post-combustion capture from coal fired power stations. Here, the membrane-cryogenic combined process is investigated for application to post-combustion carbon capture from the flue gas of a Natural Gas Combined Cycle (NGCC) process. This process involves a three-membrane process, where the combustion air is used as the sweep gas on the second membrane stage to recycle $\mathrm{CO}_{2}$ through the turbine. This ensures high $\mathrm{CO}_{2}$ recovery and also increases the $\mathrm{CO}_{2}$ partial pressure in the flue gas. The three- $\mathrm{CO}_{2}$-selective membrane process with liquefaction and $\mathrm{O}_{2}$-enrichment was found to have a cost of capture higher than the corresponding process for coal post-combustion capture. This was attributed to the large size and energy duty of the gas handling equipment, especially the feed blower, because of the high gas throughput in the system caused by significant $\mathrm{CO}_{2}$ recycling. In addition, the economics were uncompetitive compared to a modelled solvent absorption processes for NGCC.
\end{abstract}

Keywords: membrane gas separation; cryogenic; NGCC; post-combustion

\section{Introduction}

Recent design developments in membrane gas separation are moving this technology towards being economically competitive for post-combustion carbon capture from coal-fired power stations $[1,2]$. Here these competitive membrane process designs are extended to post-combustion capture from a Natural Gas Combined Cycle (NGCC) process, to evaluate the viability of membrane technology.

Traditionally, membrane-based carbon capture has only been considered for natural gas sweetening before NGCC [3] and for pre-combustion capture before the IGCC process [4], while post-combustion capture has only been studied in depth using solvent absorption [5-9], or as a novel Integrated Gasification Combined Cycle (IGCC) process with flue gas recycling [10]. This is because for NGCC the flue gas has a low $\mathrm{CO}_{2}$ partial pressure which has previously been seen as a limitation for membrane gas separation. Belaissaoui et al. [11] recently proposed overcoming this for membrane systems through flue gas recycle, where some of the $\mathrm{CO}_{2}$ produced is recycled through the gas turbine resulting in a higher $\mathrm{CO}_{2}$ partial pressure. Similar flue gas recycle has been proposed for solvent absorption technology for NGCC [12]. For coal post-combustion, flue gas recycling has been shown by Merkel et al. [2] to make membrane separation viable for post-combustion capture from a coal-fired power station. In that case, the process consists of three $\mathrm{CO}_{2}$-selective membrane stages with a cryogenic liquefaction process for $\mathrm{CO}_{2}$ separation. Sweep gas on the second membrane stage is 
designed to recycle $\mathrm{CO}_{2}$ through the coal burner, and importantly enable the entire membrane process to operate at low pressure. This differs from Belaissaoui et al. process, which requires compression before the membrane stage. The three stages membrane process is able to recover over $90 \%$ of the $\mathrm{CO}_{2}$ and achieves a product purity of over $95 \% \mathrm{CO}_{2}$ at a cost of capture comparable with current state-of-art solvent absorption technology. Hence, the three membrane stage combination presents itself as the current state of the art membrane process for post-combustion capture. As such, the three membrane stages design is applied here to post-combustion carbon capture from a NGCC process. This differs from Belaissaoui et al. design, in that the process presented here operates at low pressures.

The capture design utilises two $\mathrm{CO}_{2}$-selective membrane stages in series to concentrate $\mathrm{CO}_{2}$ in the permeate stream of the first membrane stage, and uses the second membrane stage to recycle $\mathrm{CO}_{2}$ back through the turbine (Figure 1). The $\mathrm{CO}_{2}$ rich permeate from the first membrane stage then undergoes water removal followed by compression and liquefaction to produce $\mathrm{CO}_{2}$ at the necessary purity. The membrane stages minimise the energy requirements of the liquefaction process by the exclusion of $\mathrm{N}_{2}$. The second membrane stage processes the retentate from the first membrane stage, and recycles $\mathrm{CO}_{2}$ back to the process feed stream through the turbine. This is possible because the combustion air for the turbine is used as a sweep gas on the second membrane stage. Combustion air as the sweep gas is a critical feature of the design to generate the pressure driving force across the membrane in order to maximise $\mathrm{CO}_{2}$ recovery while minimising membrane area and energy duty. However, recycling $\mathrm{CO}_{2}$ through the turbine (known as exhaust gas recirculation (EGR)) can result in limitations to the overall efficiency because of flame stability issues, incomplete oxidation of $\mathrm{CO}$ and changes to convection thermal transfer [13]. The third $\mathrm{CO}_{2}$-selective membrane stage recovers $\mathrm{CO}_{2}$ from the liquefaction column off-gas and recycles the permeate stream back to the first membrane stage permeate stream. The retentate from the third membrane stage is recycled back to the first membrane stage feed stream. This ensures all the $\mathrm{CO}_{2}$ around the liquefaction process is recovered while minimising the cooling duty.

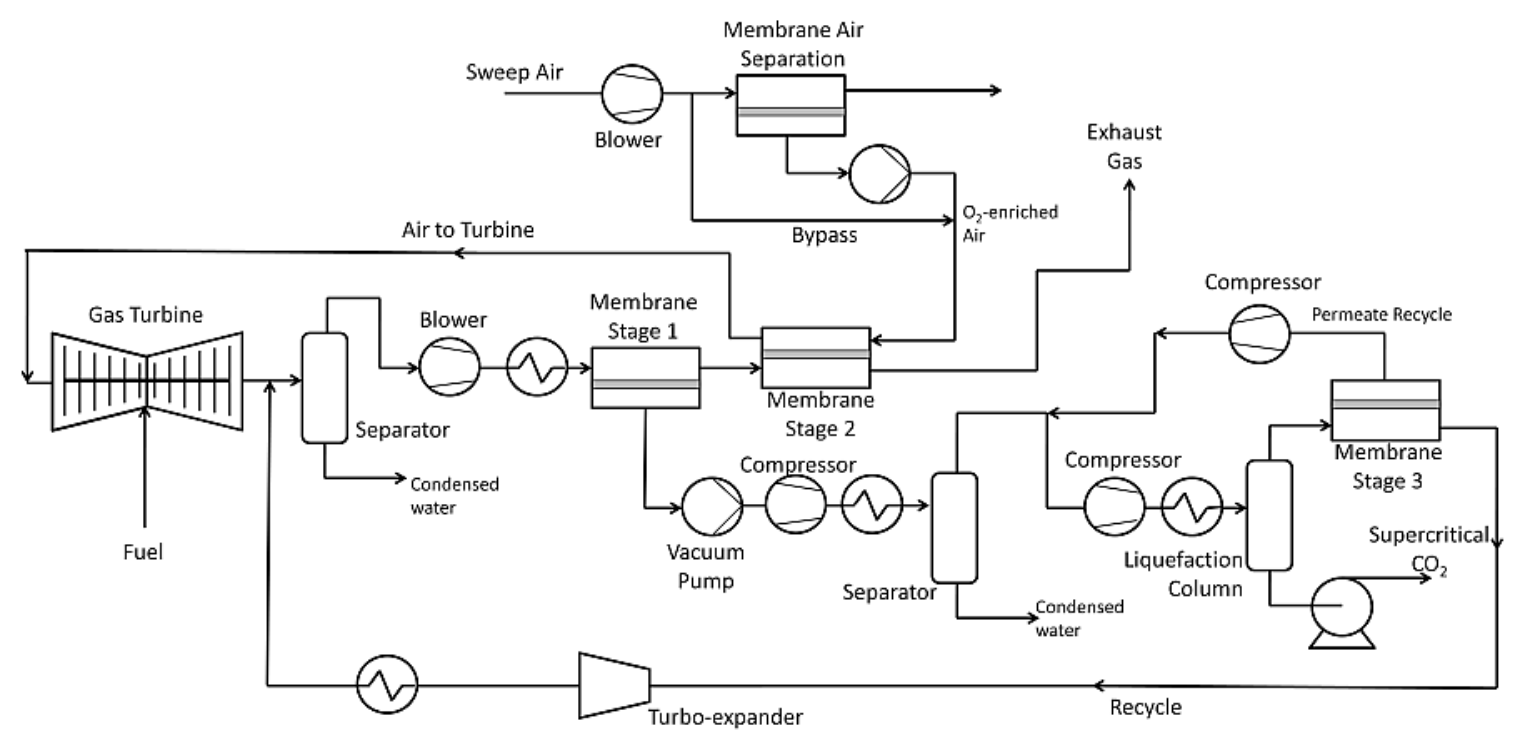

Figure 1. Three $\mathrm{CO}_{2}$-membrane stages with liquefaction and $\mathrm{O}_{2}$-enrichment for post-combustion capture from a gas turbine.

The recycling of $\mathrm{CO}_{2}$ through the turbine also has the problem of reducing the $\mathrm{O}_{2}$ partial pressure in the combustion zone, and hence reduces the efficiency of the turbine because of incomplete combustion. Therefore, in this paper we have introduced a fourth $\mathrm{O}_{2}$-enrichment membrane stage on the combustion air upstream of the second membrane stage to counter the problem of reduced $\mathrm{O}_{2}$ partial pressure. This increases the $\mathrm{O}_{2}$ concentration of combustion air/sweep gas and ensures the 
correct $\mathrm{O}_{2}$ partial pressure is present in the gas turbine, as well as lowering $\mathrm{N}_{2}$ concentration to ensure the volumetric flowrate is similar to that of the non-EGR NGCC process. Substituting $\mathrm{CO}_{2}$ for $\mathrm{N}_{2}$ in the process will impact blade cooling, convection transfer and Heat Recovery Steam Generator (HRSG) operations [14]. However, the concept of $\mathrm{O}_{2}$ enrichment of the combustion air has previously been considered for oxy-fuel NGCC capture and is likely to be applicable in this configuration [10].

To enable comparison with other carbon capture technologies, economic analysis of the carbon capture options is also presented [15].

\section{Methodology}

\subsection{Experimental}

Aspen HYSYS software package (AspenTech, Bedford, MA, USA), version 7.5, was used for all simulations. The fluid package was Peng-Robinson, which is reliable over a wide range of temperatures and pressures, and has previously been applied to $\mathrm{CO}_{2}$ capture [16,17]. The gas separation membrane process was based on an in-house programmed module, using standard mass transfer equations for cross-flow and counter-flow configurations [18].

In the Aspen HYSYS simulations all units where operated with their default parameters, with pressure drop in piping negligible, while pumps, compressors and turbo-expanders operating at $75 \%$ efficiency. The membrane's $\mathrm{CO}_{2}$ permeance was set at $1000 \mathrm{GPU}$, with a $\mathrm{CO}_{2} / \mathrm{N}_{2}$ selectivity of 50. This permeance and selectivity matches MTR's Polaris membrane and is within the membrane performance range suggested for post-combustion capture by Merkel et al. [2] The $\mathrm{O}_{2}$ permeance was assumed equal to $\mathrm{N}_{2}$, while the $\mathrm{H}_{2} \mathrm{O}$ permeance was held constant at $10,000 \mathrm{GPU}$, consistent with literature [19]. A pressure drop of $10 \mathrm{kPa}$ was assumed across both sides of the membrane stages. To ensure flow through the first and second membrane stages, the feed blower compressed the gas to $150 \mathrm{kPa}$. The first and third membrane stages were operated in a cross-flow configuration, while the second membrane stage with air sweep was operated in counter-current flow configuration. The $\mathrm{O}_{2}$-enrichment membrane was based on a cross-flow Air Products PRISM membrane process, with a blower on the feed to ensure flow through the membrane as well as the second membrane stage. A vacuum $(22 \mathrm{kPa})$ on the air separation membrane permeate stream generates the pressure driving force. The $\mathrm{O}_{2}$-enrichment was to $50 \%$, and the $\mathrm{O}_{2}$ partial pressure of the combustion air controlled through a bypass stream around the $\mathrm{O}_{2}$-enrichment membrane.

The permeate stream from the first $\mathrm{CO}_{2}$-selective membrane was compressed to $25 \mathrm{bar}$ and cooled to $15^{\circ} \mathrm{C}$ to remove the bulk of the water. The dry gas was then cooled to $-20^{\circ} \mathrm{C}$ and sent to a separator to recover liquefied $\mathrm{CO}_{2}$ at high purity. The off-gas from the separator was sent through a third $\mathrm{CO}_{2}$-selective membrane to ensure high $\mathrm{CO}_{2}$ recovery. Plasticization of the membrane at this pressure condition is possible, but not considered in these simulations as this third membrane stage has a minor role in the overall process ensuring recovery. Cooling duty was supplied by an ammonia based refrigeration cycle. All designs were set to capture over $90 \%$ of the $\mathrm{CO}_{2}$ from the flue gas and achieve at least $95 \%$ purity of $\mathrm{CO}_{2}$ in the product stream.

\subsection{Economics}

The capital expenditure (CAPEX) estimates for individual pieces of equipment were determined by Aspen's Economic Evaluation package, 2010 1st Quarter, with default parameters. The cost of the $\mathrm{CO}_{2}$ selective membrane was taken from Merkel et al. [2] at US\$50/ $\mathrm{m}^{2}$, with a membrane installation factor of 1.6. The cost of the $\mathrm{O}_{2}$-enrichment membrane was US $\$ 20 / \mathrm{m}^{2}$, with a membrane installation factor of 1.6, the cost difference recognises this is mature technology. The CAPEX of the total process was the sum of the individual equipment costs, plus US\$10 million for flue gas pretreatment. An additional loading of $25 \%$ was added to account for instrumentation, piping and electrical costs, plus an additional $13 \%$ for engineering and start-up costs. A final additional 10\% was added as a project contingency to the CAPEX, in keeping with literature [20]. For operating 
expense (OPEX) estimates, the cost of electricity was $\$ 0.0576 / \mathrm{kWh}$ for NGCC which corresponds to a natural gas price of about US\$5.81 per GJ [21]. Also included was a 5 year replacement period for all membranes and a $6 \%$ maintenance cost. To simplify the process simulations all membrane separation performance was assumed constant over this time period (i.e., no aging). The project life was 25 years, with 2 years construction period and $85 \%$ load factor. The real discount rate was $7 \%$. The economics presented here do not take into account the transportation or injection of the $\mathrm{CO}_{2}$ product stream for geo-sequestration. Full details of the economic methodology can be found in Ho et al. [20].

The post-combustion flue gas conditions and composition are from a Natural Gas Combined Cycle power plant, based on a net output of $300 \mathrm{MW}$ [5], provided in Table 1.

Table 1. Flue gas conditions and composition from a Natural Gas Combined Cycle (NGCC) process, which is the basis of the process simulations.

\begin{tabular}{cc}
\hline Flue gas conditions & NGCC \\
\hline Flowrate (tonne $/ \mathrm{hr})$ & 2268 \\
Temperature $\left({ }^{\circ} \mathrm{C}\right)$ & 100 \\
Composition $(\mathrm{mol} \%)$ & - \\
$\mathrm{CO}_{2}$ & 4.97 \\
$\mathrm{~N}_{2}$ & 74.28 \\
$\mathrm{O}_{2}$ & 9.73 \\
$\mathrm{H}_{2} \mathrm{O}$ & 11.02 \\
\hline
\end{tabular}

\section{Results and Discussion}

The combination of two membrane stages with $\mathrm{CO}_{2}$ recycle through the turbine overcomes the limitation experienced with only one membrane stage; that is choosing between recovery or purity in the permeate stream. The two $\mathrm{CO}_{2}$-selective membrane stages in series on the flue gas feed enables both high $\mathrm{CO}_{2}$ recovery and high $\mathrm{CO}_{2}$ purity to be achieved in the permeate stream of the first membrane stage. This ensures that $\mathrm{N}_{2}$ is excluded from the liquefaction process and reduces the subsequent compression and cooling duty. In a NGCC power plant with capture, an important parameter in the design is the amount of $\mathrm{CO}_{2}$ being recycled through the turbine, via the combustion air sweep gas. This is varied by alternating the relative $\mathrm{CO}_{2}$ recovery in the first and second membrane stages, while always ensuring that the combined $\mathrm{CO}_{2}$ recovery is greater than $90 \%$. The amount of $\mathrm{CO}_{2}$ being recycled through the turbine in this analysis is varied between $2.5 \%$ and $30 \%$, with literature suggesting the impact from the higher recycle level, while significant, is within operational conditions of gas turbines [22]. Where a small recovery in the first membrane stage results in a significant amount of $\mathrm{CO}_{2}$ being recycled via the second membrane stage and vice versa. Importantly, the two stage membrane process ensures that the $\mathrm{CO}_{2}$ purity in the first stage permeate stream is always above $75 \%$, irrespective of the individual membrane stage recoveries.

Altering the amount of $\mathrm{CO}_{2}$ being recycled through the process impacts the equipment size and energy duty. A large $\mathrm{CO}_{2}$ recycle reduces the membrane area for both the first and second membrane stages, because of the higher partial pressure. However, a large recycle rate also increases the energy duty of the process as the feed blower must handle increased throughput. This represents a trade-off between equipment cost through reduced membrane area and increased energy duty. The impact $\mathrm{CO}_{2}$ recycle has on cost of capture is shown in Figure 2. The NGCC process achieves a minimum in the cost of capture when the $\mathrm{CO}_{2}$ recycle going through the turbine is 0.25 mole fraction for NGCC. At lower $\mathrm{CO}_{2}$ recycle rates, the membrane area of the first and second stages are substantially large because the $\mathrm{CO}_{2}$ partial pressure is low, producing only a small driving force for separation. This resulted in a substantial CAPEX due to significant increases in membrane cost as well as OPEX increase because of higher membrane replacement cost. In contrast, at higher $\mathrm{CO}_{2}$ recycle of 0.3 , there is a smaller membrane area, but the increase in energy demand of the feed blower, and a significant increase in OPEX offsets any reduction in membrane CAPEX. In terms of the gas turbine, operating the NGCC 
process with the combustion air having a $\mathrm{CO}_{2}$ mole fraction of 0.24 is theoretically possible. However, industrial testing will be required to demonstrate its feasibility.

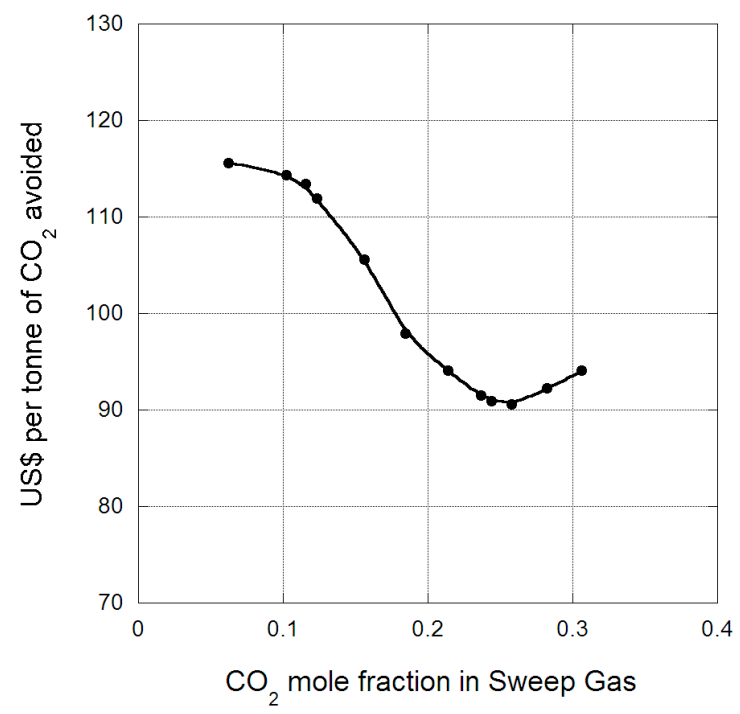

Figure 2. Cost of capture (US\$ per tonne of $\mathrm{CO}_{2}$ avoided) for NGCC as a function of recycle $\mathrm{CO}_{2}$ mole fraction.

For the NGCC scenario where the recycle rate is 0.24 , the combined $\mathrm{CO}_{2}$-selective membrane area is $3.3 \times 10^{5} \mathrm{~m}^{2}$, which is comparable with existing natural gas sweetening membrane areas [3]. Of the $\mathrm{CO}_{2}$-selective membranes, the total area is mostly associated with the second membrane stage, given the high $\mathrm{CO}_{2}$ recycle through the turbine, while the third membrane stage area is less than $100 \mathrm{~m}^{2}$ to recycle the small amount of $\mathrm{CO}_{2}$ in the off-gas from the liquefaction process and the first membrane requires an area of about $1.6 \times 10^{4} \mathrm{~m}^{2}$. In comparison the $\mathrm{O}_{2}$-enrichment process membrane area is $7.9 \times 10^{5} \mathrm{~m}^{2}$. This area is more than double that of the $\mathrm{CO}_{2}$-selective membranes, and indicates the quantity of air for combustion needed to be processed to ensure the correct $\mathrm{O}_{2}$ partial pressure in the turbines.

As shown in Figure 2, the cost of post-combustion capture for a NGCC power plant with a combined three- $\mathrm{CO}_{2}$ selective membrane process and $\mathrm{O}_{2}$-enrichment membrane has a minimum capture cost of US\$91 per tonne of $\mathrm{CO}_{2}$ avoided. This cost is greater than values reported for post-combustion NGCC capture using solvent technology. For a Fluor solvent the cost of capture is US\$58 per tonne of $\mathrm{CO}_{2}$ avoided, and with a MHI solvent the cost of capture is US\$48 per tonne of $\mathrm{CO}_{2}$ avoided [23]. The corresponding energy penalties for these processes are about $15 \%$ and $11 \%$ respectively. It should be noted that these costs are for a $776 \mathrm{MW}$ NGCC process with the same operating lifetime and load factor, but a higher COE at $\$ 0.067 / \mathrm{kWh}$. As such, the results suggest that the membrane process does not compete with solvent technology for NGCC. Furthermore, the cost for the proposed post-combustion NGCC membrane process has been shown to be lower if used at a supercritical coal-fired power station, with reported values of US\$28-US\$32 per tonne of $\mathrm{CO}_{2}$ avoided [24]. One of the main reasons for the difference in cost is the lower $\mathrm{CO}_{2}$ purity in the liquefaction process, 0.75 for the post-combustion NGCC compared to $0.9 \mathrm{CO}_{2}$ mole fraction in the coal-fired power station process. This increases the energy duty for the vacuum pump, compressor and cooling. For the NGCC process the energy demand is 35\% (117 MW). Hence, over a third of the power output from the power plant is consumed by the capture plant, whilst for the coal power plant it was less than $30 \%$.

The breakdown of the energy duty for the capture plant is provided in Figure 3. The feed blower accounts for almost half of the energy duty of the capture plant. This unit operation is a blower, not a compressor, as it provides the necessary pressure $(150 \mathrm{kPa})$ for the flue gas to pass through 
membrane stages 1 and 2. The significant energy duty is because of the large amount of $\mathrm{CO}_{2}$ recycle and considerable gas throughput in the process. The next major component, accounting for over a quarter of the energy demand is the vacuum pump on the first membrane stage to ensure sufficient partial pressure driving force across the membrane module. Hence, gas handling accounts for three quarters or more of the energy demand of this capture process, and highlights the major limitation of achieving significant energy savings for membrane processes with low $\mathrm{CO}_{2}$ partial pressure systems. The refrigeration cooling duty in the liquefaction process accounts for $19 \%$.

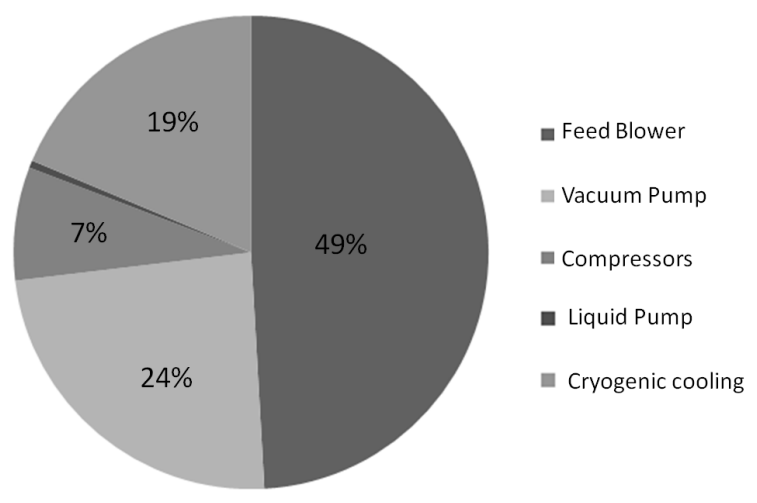

Figure 3. Energy duty breakdown of the membrane-liquefaction process.

The $\mathrm{CO}_{2} / \mathrm{N}_{2}$ selectivity is a major membrane variable as it controls the purity of $\mathrm{CO}_{2}$ entering the liquefaction process. Improving the selectivity reduces both the compression and cooling duty of the process, because of exclusion of $\mathrm{N}_{2}$ from the liquefaction process. This represents a reduction in cost of capture, as shown in Figure 4 for the NGCC process. The cost of capture falls as selectivity increases and reaches a plateau at $\mathrm{CO}_{2} / \mathrm{N}_{2}=150$. Above this selectivity there is no savings made in the cost of capture because essentially enough of the $\mathrm{N}_{2}$ has been excluded from the permeate stream in the first membrane stage to meet the required $\mathrm{CO}_{2}$ concentration for storage, once water has been removed. At this selectivity, the cost of capture reduces to about US\$83 per tonne of $\mathrm{CO}_{2}$ avoided, though it is still higher than conventional solvent technology. However, while a number of polymeric membrane materials have reported selectivities this high [25], to the authors' knowledge none have been commercialized. One of the current best performing membrane for post-combustion capture is MTR's Polaris, which has a $\mathrm{CO}_{2} / \mathrm{N}_{2}$ selectivity of 50 [2]. Hence, to obtain these potential decreases in cost of capture, further development of membrane materials and improvement in selectivity will be required.

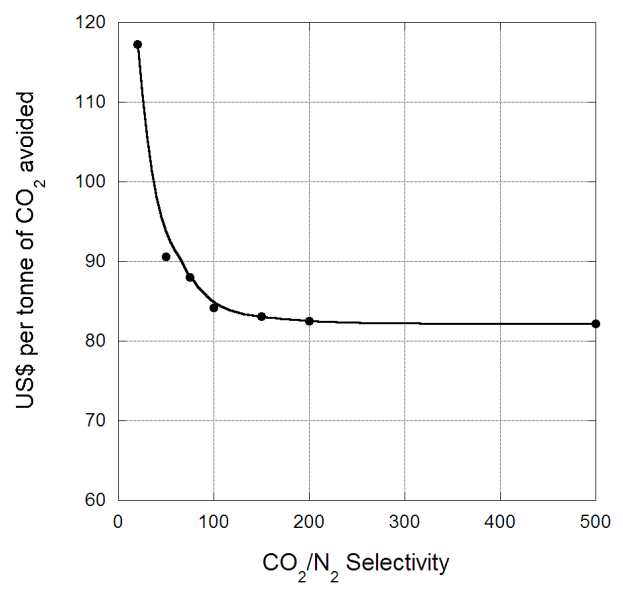

Figure 4. Cost of capture (US\$ per tonne of $\mathrm{CO}_{2}$ avoided) for NGCC as a function of membrane $\mathrm{CO}_{2} / \mathrm{N}_{2}$ selectivity. 
The CAPEX breakdown of the capture plant is provided in Figure 5. The biggest capital expense is the blower/compressor/vacuum pump for gas handling. The next biggest expense is the general cost, of piping, instrumentation, etc. The $\mathrm{CO}_{2}$-selective membranes contribute $18 \%$ to the CAPEX. Hence, to achieve a CAPEX reduction, savings must be made to the gas handling equipment, in particular the feed blower which accounts for $26 \%$ of the CAPEX.

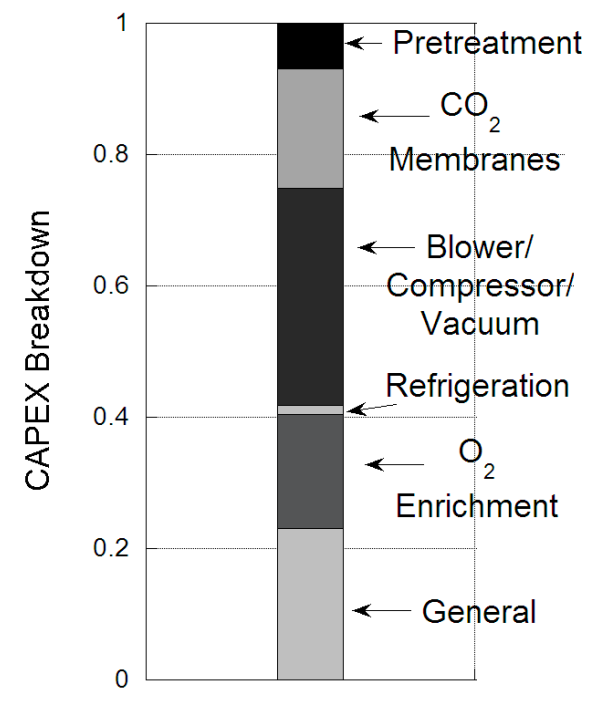

Figure 5. CAPEX breakdown of NGCC post-combustion membrane capture plant.

The OPEX breakdown is provided in Figure 6. Again, the biggest contribution is the energy cost for gas handling, account for 50\%. The next largest contributor to the OPEX is the general cost, including cooling water and plant maintenance. The refrigeration duty is $3 \%$ of the OPEX, $\mathrm{O}_{2}$ enrichment process is $7 \%$, because of the high air throughput, while membrane replacement is less than $7 \%$.

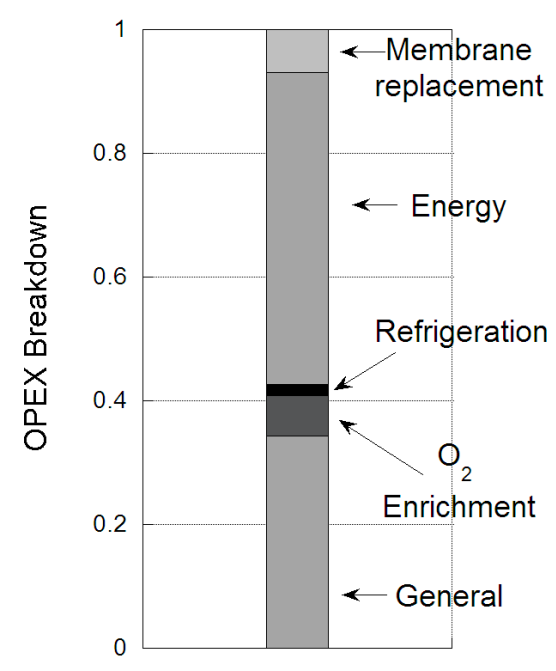

Figure 6. OPEX breakdown of NGCC post-combustion membrane capture plant.

One option to reduce the cost of capture could be to eliminate the feed blower from the process, given that it accounts for almost half the energy duty of the process because of the high gas throughput. This will require the exhaust gas from the Heat Recovery Steam Generator (HRSG) to be at sufficient pressure to ensure flow through the associated duct work. However, reducing the HRSG back pressure results in a reduction to the power output and efficiency of the combined cycle, $\sim 0.25 \%$ loss per 
$50 \mathrm{mbar}$ [26]. Removing the blower and incorporating the power loss because of increased flue gas pressure, indicates that the energy demand for the membrane capture plant becomes $60 \mathrm{MW}$, and reduces the parasitic load on the NGCC plant to $20 \%$. The cost of capture for the process without the feed blower is provided in Figure 7, as a function of membrane $\mathrm{CO}_{2} / \mathrm{N}_{2}$ selectivity. At a $\mathrm{CO}_{2} / \mathrm{N}_{2}$ selectivity of 50, the cost of capture for NGCC reduces to US $\$ 67$ per tonne of $\mathrm{CO}_{2}$ avoided if the blower is excluded, which represents a saving of $26 \%$ compared to the baseline case. Again, the cost of capture reduces with increased selectivity until it reaches a constant value at $\mathrm{CO}_{2} / \mathrm{N}_{2}=200$, because of the high $\mathrm{CO}_{2}$ purity in the permeate stream eliminates the need for liquefaction.

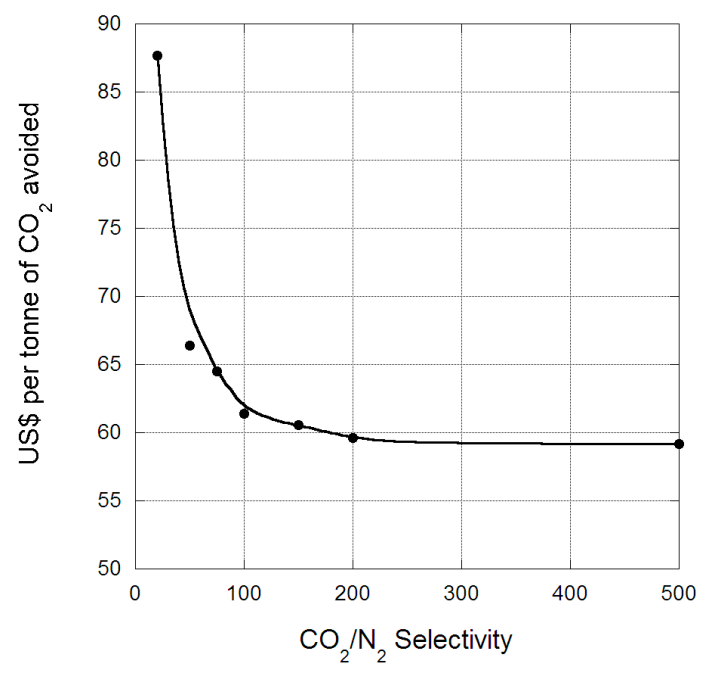

Figure 7. Cost of capture (US\$ per tonne of $\mathrm{CO}_{2}$ avoided) for NGCC as a function of membrane $\mathrm{CO}_{2} / \mathrm{N}_{2}$ selectivity, with no blower.

\section{Conclusions}

A three- $\mathrm{CO}_{2}$-selective membrane with liquefaction and $\mathrm{O}_{2}$-enrichment process was shown not to be competitive for post-combustion carbon capture compared to conventional chemical absorption technology when applied to the flue gas of NGCC. The process achieves a minimum in cost of capture when a significant amount of $\mathrm{CO}_{2}$ is recycled through the turbine in the combustion air. The feed blower accounts for almost half of the energy duty of the plant, due to the high gas throughput. This highlights the strong dependence the membrane-liquefaction process design has on $\mathrm{CO}_{2}$ partial pressure in the flue gas to be competitive with other $\mathrm{CO}_{2}$ separation technologies.

Acknowledgments: The authors would like to thank the Cooperative Research Centre for Greenhouse Gas Technologies (CO2CRC) for funding.

Author Contributions: Colin A. Scholes and Minh T. Ho conceived and designed the experiments; Colin A. Scholes performed the process simulations; Minh T. Ho undertook the economic analysis; Colin A. Scholes, Minh T. Ho and Dianne E. Wiley analyzed the data and wrote the paper. All authors have read and approved the final manuscript.

Conflicts of Interest: The authors declare no conflict of interest.

\section{Reference}

1. Favre, E.; Bounaceur, R.; Roizard, D. A hybrid process combining oxygen enriched air combustion and membrane separation for post-combustion carbon dioxide capture. Sep. Purif. Technol. 2009, 68, 30-36. [CrossRef]

2. Merkel, T.C.; Lin, H.; Wei, X.; Baker, R. Power plant post-combustion carbon dioxide capture: An opportunity for membranes. J. Membr. Sci. 2010, 359, 126-139. [CrossRef] 
3. Scholes, C.A.; Stevens, G.W.; Kentish, S.E. Membrane gas separation applications in natural gas processing. Fuel 2012, 96, 15-28. [CrossRef]

4. Scholes, C.A.; Smith, K.H.; Kentish, S.E.; Stevens, G.W. $\mathrm{CO}_{2}$ capture from pre-combustion processes-Strategies for membrane gas separation. Int. J. Greenh. Gas Control 2010, 4, 739-755. [CrossRef]

5. Amann, J.-M.G.; Bouallou, C. $\mathrm{CO}_{2}$ capture from power stations running with natural gas (NGCC) and pulverized coal (PC): Assessment of a new chemical solvent based on aqueous solutions of n-methyldiethanol amine + triehtylene tetramine. Energy Procedia 2009, 1, 909-916. [CrossRef]

6. Falk-Pedersen, O.; Bjerve, Y.; Glittum, G.; Ronning, S. Separation of carbon dioxide from offshore gas turbine exhaust. Energy Convers. Manag. 1995, 6-9, 393-396. [CrossRef]

7. Li, H.; Haugen, G.; Ditaranto, M.; Berstad, D.; Jordal, K. Impacts of exhaust gas recirculation (egr) on the natural gas combined cycle integrated with chemical absorption $\mathrm{CO}_{2}$ capture technology. Energy Procedia 2011, 4, 1411-1418. [CrossRef]

8. Mofarahi, M.; Khojasteh, Y.; Khaledi, H.; Farahnak, A. Design of $\mathrm{CO}_{2}$ absorption plant for recovery of $\mathrm{CO}_{2}$ from flue gases of gas turbine. Energy 2008, 33, 1311-1319. [CrossRef]

9. Peeters, A.N.M.; Faaij, A.P.C.; Turkenburg, W.C. Techno-economic analysis of natural gas combined cycles with post-combustion $\mathrm{CO}_{2}$ absorption, including a detailed evaluation of the development potential. Int. J. Greenh. Gas Control 2007, 1, 396-417. [CrossRef]

10. Shao, Y.; Golomb, D. Power plants with $\mathrm{CO}_{2}$ capture using integrated air separation and flue gas recycling. Energy Convers. Manag. 1996, 37, 903-908. [CrossRef]

11. Belaissaoui, B.; Cabot, G.; Cabot, M.-S.; Willson, D.; Favre, E. An energetic analysis of $\mathrm{CO}_{2}$ capture on a gas turbine combining flue gas recirculation and membrane separation. Energy 2012, 38, 167-175. [CrossRef]

12. Shao, Y.; Golomb, D.; Brown, G. Natural gas fired combined cycle power plant with $\mathrm{CO}_{2}$ capture. Energy Convers. Manag. 1995, 36, 1115-1128. [CrossRef]

13. Sipocz, N.; Tobiesen, A.; Assadi, M. Integrated modelling and simulation of a 400 MW NGCC power plant with $\mathrm{CO}_{2}$ capture. Energy Procedia 2011, 4, 1941-1948. [CrossRef]

14. Bolland, O.; Mathieu, P. Comparison of two $\mathrm{CO}_{2}$ removal options in combined cycle power plants. Energy Convers. Manag. 1998, 39, 1653-1663. [CrossRef]

15. Allinson, G.; Ho, M.T.; Neal, P.N.; Wiley, D.E. The methodology used for estimating the costs of CCS. In Proceedings of the 8th International Conference on Greenhouse Gas Technologies, Tronheim, Norway, 19-22 June 2006.

16. Desideri, U.; Paolucci, A. Performance modelling of a carbon dioxide removal system for power plants. Energy Convers. Manag. 1999, 40, 1899-1915. [CrossRef]

17. Scholes, C.A.; Anderson, C.J.; Cuthbertson, R.; Stevens, G.W.; Kentish, S.E. Simulations of membrane gas separation: Chemical solvent absorption hybrid plants simulations for pre- and post-combustion carbon capture. Sep. Sci. Technol. 2013, 48, 1954-1962. [CrossRef]

18. Zolandz, R.R.; Fleming, G.K. Design of gas separation systems. In Membrane Handbook; Ho, W.S.W., Sirkar, K.K., Eds.; Kluwer Academic: Norwell, MA, USA, 1992; pp. 54-77.

19. Scholes, C.A.; Kentish, S.E.; Stevens, G.W. Effects of minor components in carbon dioxide capture using polymeric gas separation membranes. Sep. Purif. Rev. 2009, 38, 1-44. [CrossRef]

20. Ho, M.T.; Allinson, G.W.; Wiley, D.E. Reducing the cost of $\mathrm{CO}_{2}$ capture from flue gases using membrane technology. Ind. Eng. Chem. Res. 2008, 47, 1562-1568. [CrossRef]

21. Fout, T.; Zoelle, A.; Keairns, D.; Turner, M.; Woods, M.; Kuehn, N.; Shah, V.; Chou, V.; Pinkerton, L. Cost and Performance Baseline for Fossil Energy Plants. Volume 1a: Bituminous Coal (pc) and Natural Gas to Electricity; National Energy Technology Laboratory, U.S. Department of Energy: Washington, DC, USA, 2015.

22. Jonshagen, K.; Sipocz, N.; Genrup, M. Optimal combined cycle for $\mathrm{CO}_{2}$ capture with EGR. In Proceedings of the ASME Turbo Expo, Glasgow, UK, 14-18 June 2010.

23. Davison, J. Performance and costs of power plants with capture and storage of $\mathrm{CO}_{2}$. Energy 2007, 32, 1163-1176. [CrossRef]

24. Scholes, C.A.; Ho, M.T.; Stevens, G.W.; Kentish, S.E. Cost competitive membrane-Cryogenic post-combustion carbon capture. Int. J. Greenh. Gas Control 2013, 17, 341-348. [CrossRef] 
25. Powell, C.E.; Qiao, G.G. Polymeric $\mathrm{CO}_{2} / \mathrm{N}_{2}$ gas separation membranes for the capture of carbon dioxide from power plant flue gases. J. Membr. Sci. 2006, 279, 1-49. [CrossRef]

26. Kehlhofer, R.; Rukes, B.; Hannemann, F.; Stirnimann, F. Combined-Cycle Gas \& Steam Turbine Power Plants; PennWell: Tulsa, OK, USA, 2009. 